\title{
Airborne verification of CALIPSO products over the Amazon: a case study of daytime observations in a complex atmospheric scene
}

\author{
F. Marenco ${ }^{1}$, V. Amiridis ${ }^{2}$, E. Marinou ${ }^{2}$, A. Tsekeri ${ }^{2}$, and J. Pelon ${ }^{3}$ \\ ${ }^{1}$ Observational Based Research, Met Office, Exeter, UK \\ ${ }^{2}$ Institute for Astronomy, Astrophysics, Space Applications and Remote Sensing, \\ National Observatory of Athens, Athens, Greece \\ ${ }^{3}$ UPMC-CNRS/INSU-UVSQ, LATMOS, 4 Place Jussieu, 75252 Paris CEDEX 05, France \\ Correspondence to: F. Marenco (franco.marenco@metoffice.gov.uk)
}

Received: 10 March 2014 - Published in Atmos. Chem. Phys. Discuss.: 4 April 2014

Revised: 3 October 2014 - Accepted: 9 October 2014 - Published: 12 November 2014

\begin{abstract}
A daytime underflight of CALIPSO with the Facility for Airborne Atmospheric Measurements was performed on 20 September 2012 in the Amazon region of Brazil, during the biomass burning season. The scene is dominated by a thin elevated layer (aerosol optical depth (AOD) 0.03 at $532 \mathrm{~nm}$ ) and a moderately turbid boundary layer (AOD $\sim 0.2$ at $532 \mathrm{~nm}$ ). The boundary layer is topped with small broken stratocumulus clouds. In this complex scene, a comparison of observations from the airborne and spaceborne lidars reveals a few discrepancies. The CALIPSO detection scheme tends to miss the elevated thin layer, and also shows several gaps $(\sim 30 \%)$ in the boundary layer. The small clouds are not correctly removed from the signals; this can cause the CALIPSO aerosol subtype to oscillate between smoke and polluted dust and may introduce distortion in the aerosol retrieval scheme. The magnitude of the average extinction coefficient estimated from CALIPSO Level 2 data in the boundary layer is as expected, when compared to the aircraft lidar and accounting for wavelength scaling. However, when the gaps in aerosol detection mentioned above are accounted for, we are left with an overall estimate of AOD for this particular scene that is of the order of two thirds of that determined with the airborne lidar.
\end{abstract}

\section{Introduction}

Biomass burning is the second largest source of anthropogenic aerosols on Earth (Houghton et al., 2001). The Fourth Assessment Report of the Intergovernmental Panel on
Climate Change reports a global radiative forcing (RF) contribution of roughly $+0.03 \pm 0.12 \mathrm{~W} \mathrm{~m}^{-2}$ for biomass burning aerosols (Forster et al., 2007), whereas the Fifth Assessment Report estimates this contribution to be $\pm 0.2 \mathrm{~W} \mathrm{~m}^{-2}$ (Stocker et al., 2013). Textor et al. (2006) showed that there are still significant uncertainties in the aerosol vertical distribution in global models, whereas this information is critical in assessing the magnitude and even the sign of the direct RF. Of particular interest are the distribution of lofted layers (Mattis et al., 2003; Müller et al., 2005; Baars et al., 2012) and the identification of complex scenes involving both aerosols and clouds (Chand et al., 2008). The large amount of heat released by forest fires can generate strong updrafts and deep convection in their vicinity, with a rapid transport of aerosols to upper layers (Freitas et al., 2007; Labonne et al., 2007; Sofiev et al., 2012). These aerosols, in turn, have an impact on cloud formation, convection, and precipitation patterns (Andreae et al., 2004; Koren et al., 2008).

Since 2006 the Cloud-Aerosol Lidar with Orthogonal Polarization (CALIOP), on board the Cloud-Aerosol Lidar and Infrared Pathfinder Satellite Observations (CALIPSO) satellite, has provided an invaluable global data set on the vertical structure of the atmosphere (Winker et al., 2010, 2013). Several studies have appeared recently, with the goal of evaluating CALIPSO products using ground-based lidar (Kim et al., 2008; Pappalardo et al., 2010; Tesche et al., 2013), the Aerosol Robotic Network (AERONET) (Mielonen et al., 2009; Schuster et al., 2012; Omar et al., 2013; Lopes et al., 2013), other satellite sensors (Kittaka et al., 2011; Redemann et al., 2012; Kim et al., 2013; Jethva et al., 2014), re- 
search aircraft (Burton et al., 2013; Amiridis et al., 2012), or comprehensive multi-platform experiments (Kacenelenbogen et al., 2011; Amiridis et al., 2013).

CALIOP has two operational wavelengths: 532 and $1064 \mathrm{~nm}$, and in the former it has dual polarisation capability (Hunt et al., 2009; Winker et al., 2010). Accurate night-time calibration of the principal channel at $532 \mathrm{~nm}$ is obtained via molecular normalisation at stratospheric levels, and the calibration is then transferred to the other channels (Powell et al., 2009). As for most lidars, daylight acts as a disturbance to the signal returns, and hence reduces the signal-to-noise ratio (SNR), with the consequence that CALIPSO's night-time data have a superior quality to the daytime data. Scenes with a large planetary albedo, e.g. those with cloud cover, will be dominated by a larger amount of daylight entering the detectors, and thus will present an even poorer SNR.

For the first time, a global and fully automated lidar data inversion procedure has been designed. CALIOP's data analysis package automatically identifies aerosol and cloud layers, and this information is stored as the vertical feature mask (VFM) and atmospheric volume description (AVD) flags (Liu et al., 2009). For aerosol layers, one of six aerosol subtypes is identified (clean marine, dust, polluted continental, clean continental, polluted dust, and smoke), and they determine the extinction-to-backscatter ratio (lidar ratio) based on a look-up table (Omar et al., 2009). Using the lidar ratio (and its uncertainty associated with the identified aerosol subtype), extinction and backscatter profiles are computed using the Hybrid Extinction Retrieval Algorithms, HERA (Young and Vaughan, 2009; Young et al., 2013). This is an iterative method that solves the lidar equation for a two-component atmosphere, with an integration that starts at the top of the atmosphere and works its way down to the surface. However, the outward solution of the lidar equation can lead to mathematical instability and divergence (Fernald, 1984; Marenco, 2013), and in the attempt to keep these unwanted effects under control, a mechanism for iterative adaptation of the lidar ratio is applied when such instabilities are detected (Young and Vaughan, 2009; Young et al., 2013). This marks a difference with the classical outward solution with a pre-assigned lidar ratio; the latter is decreased as is needed to reach stability and offers the advantage of exploiting the forward inversion down to the surface, in terms of vertical extension.

In this paper we examine an underpass of the CALIPSO satellite by the Facility for Airborne Atmospheric Measurements (FAAM) BAe-146 research aircraft, during a daytime flight in the Amazon basin during the biomass burning season. Although limited, this data set gives a good insight on some critical aspects that may be associated with CALIPSO retrievals and the characterisation of aerosol subtypes.
Table 1. Technical specifications of the Leosphere ALS450 lidar on board the FAAM aircraft. Footprints are computed for a typical aircraft speed of $150 \mathrm{~m} \mathrm{~s}^{-1}$.

\begin{tabular}{ll}
\hline Wavelength & $355 \mathrm{~nm}$ \\
Pulse energy & $12 \mathrm{~mJ}$ \\
Repetition frequency & $20 \mathrm{~Hz}$ \\
Receiver aperture & $15 \mathrm{~cm}$ \\
Receiver bandwidth & $0.36 \mathrm{~nm}$ \\
Overlap range & $300 \mathrm{~m}$ \\
Raw data vertical resolution & $1.5 \mathrm{~m}$ \\
Processed data vertical resolution* & $45 \mathrm{~m}$ \\
Raw data integration time* & $2 \mathrm{~s}$ (footprint $0.3 \mathrm{~km}$ ) \\
Processed data integration time* & $10 \mathrm{~s}$ (footprint $1.5 \mathrm{~km}$ ) \\
\hline
\end{tabular}

* user-configurable parameter.

\section{Aircraft observations}

In September and October 2012 the South AMerican Biomass Burning Analysis (SAMBBA) campaign was carried out in Brazil, and several observations were made during 20 science flights using both in situ and remote sensing techniques (Angelo, 2012; Johnson et al., 2013). Significant aerosol loading has been found during most of the flights, and in the majority of cases it has been ascribed to smoke originating from forest fires, as confirmed by a variety of measurements. In situ observations with wing-mounted optical particle counters (PCASP and CDP; see Liu et al., 1992; Lance et al., 2010) showed a predominance of fine mode particles. Moreover, measurements with the on board AL 5002 VUV Fast Fluorescence CO Analyser (Gerbig et al., 1996, 1999; Palmer et al., 2013) showed high carbon monoxide concentrations. No strong depolarisation signal has been observed in the aircraft lidar returns, except when observing optically thick layers where multiple scattering is non-negligible (clouds and very thick smoke). A general feature throughout the campaign was the persistence of aerosols above the boundary layer, with thin plumes up to altitudes of 5-7 km, presumably due to lifting via deep convection.

On 20 September a complex flight was carried out, taking off from Porto Velho, Brazil, and flying over the Amazon for three hours and $45 \mathrm{~min}$ (flight number B737, see Fig. 1). Most of the flight was devoted to characterising a large natural wildfire, but towards the end a $230 \mathrm{~km}$ long underpass of CALIPSO was performed (this distance was covered in $33 \mathrm{~s}$ by CALIPSO, and $24 \mathrm{~min} 30 \mathrm{~s}$ by the aircraft). This paper focuses on the latter part of the flight (Run 19), when clouds and aerosol layers have been mapped with the airborne lidar looking down from $6500 \mathrm{~m}$.

An ALS450 lidar system, manufactured by Leosphere, was used on board the aircraft, looking down at nadir (Marenco et al., 2011). For a description of the lidar system, see Chazette et al. (2012); see also Table 1 for the system's specifications. The receiver implements two channels, for the 


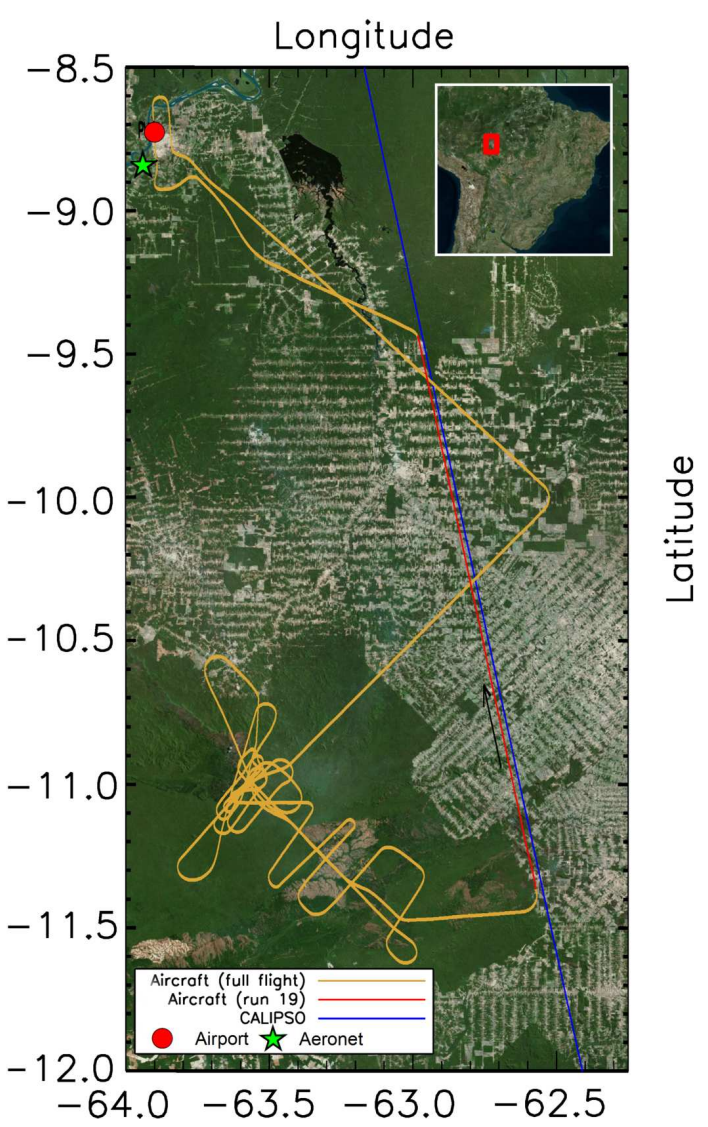

Figure 1. Yellow line: full flight track of the BAe-146 aircraft on 20 September 2012 (flight B737). Red line: aircraft track for the flight section between 17:49:20 and 18:12:46 UTC (Run 19). Blue line: CALIPSO footprint on the same date, between 18:00:37 and 18:01:41 UTC. Porto Velho is marked near the top left corner: red circle, airport; green star, AERONET site.

detection of the elastic backscatter in both the co-polar and the cross-polar planes, relative to the emitted radiation. Unfortunately, the system suffers large temperature variations during a research flight, which strongly affects the depolarisation signal; for this reason it is not possible to use depolarisation quantitatively (it cannot be calibrated) and depolarisation information is used qualitatively. For non-depolarising aerosol layers, this is believed to have little impact on the retrieved extinction profile.

Lidar signals have been acquired with an integration time of $2 \mathrm{~s}$ (40 laser shots) and a vertical resolution of $1.5 \mathrm{~m}$; to reduce random noise, all vertical profiles have been further smoothed with a 30-point running average. The rangecorrected lidar signal that is displayed in the present paper has, therefore, a horizontal resolution of $0.3 \mathrm{~km}(2 \mathrm{~s}$ at $\sim 150 \mathrm{~m} \mathrm{~s}^{-1}$, speed of the aircraft) and a vertical resolution of $45 \mathrm{~m}$. For this product, the SNR is larger than $\sim 5$ on the whole atmospheric column, for a daytime cloud-free profile with moderate aerosol load (aerosol optical depth, AOD 0.3), when looking down from an altitude of $6500 \mathrm{~m}$.
Lidar signals have been integrated to a $10 \mathrm{~s}$ resolution (1.5 km footprint) for further analysis. Cloud screening has been performed by discarding whole vertical profiles at the $10 \mathrm{~s}$ resolution, if they contained cloud signals, where clouds have been automatically detected using the thresholds given in Osborne et al. (2014) and Allen et al. (2014), and have been manually validated after a profile-by-profile signal inspection. The remaining lidar signals have then been processed with the method described in Marenco (2013), using a lidar ratio of $75 \mathrm{sr}$, appropriate for biomass burning aerosols (Baars et al., 2012; Groß et al., 2012); this processing is achieved for whole vertical profiles at once.

Finally, to offer a better comparison with the CALIPSO product, the extinction coefficient obtained with the aircraft lidar has been converted to $532 \mathrm{~nm}$; the conversion is achieved by applying a colour ratio $0.57 \pm 0.01$, derived from the nearby AERONET station in Porto Velho (mean and standard deviation of the direct-sun measurements taken on 20 September). This wavelength conversion has to be considered approximate, because the spectral absorption properties of the aerosols may vary; moreover, the AERONET site is located $\sim 200 \mathrm{~km}$ to the Northwest (see, Anderson et al., 2003 for the coherent spatial scales of extensive aerosol properties). We believe, however, that this approach is reasonable because (i) our flights over the Amazon have shown a large degree of coherence of the regional haze over distances of several hundreds of kilometres, and (ii) colour ratio is an intensive property of the aerosols, and thus presumed to be consistent over large scales than the extensive properties. The colour ratio we have found is compatible with the wavelength dependence derived by Baars et al. (2012) using Raman lidar data, since that article indicates an Ångström exponent of $1.17 \pm 0.44$, which corresponds to a colour ratio $0.62 \pm 0.11$.

\section{Results}

Figure 2a shows the range corrected signal measured from the airborne lidar at $355 \mathrm{~nm}$. A thin elevated aerosol layer is highlighted at $4500-5000 \mathrm{~m}$ with some other thinner layers underneath it but well above the boundary layer. The elevated layer was observed by lidar during all the high altitude portions of this flight. At the top of the boundary layer $(\sim 2.2 \mathrm{~km}$ ), a series of small broken clouds can be seen (stratocumulus), displayed in dark red since their lidar returns are very large and saturate the colour scale. The size of the clouds can be estimated from the airborne lidar: their alongtrack horizontal extent ranges from $\sim 0.3$ to $5 \mathrm{~km}$ (median $1.2 \mathrm{~km}$ ), except for a wider cloudy area at the Northern end that has a horizontal extent of $20 \mathrm{~km}$. Cloud cover is estimated to be $36 \%$ (fraction of aircraft lidar profiles where a cloud is detected). Low returns are found in the boundary layer (blue colour): one could be mislead into thinking that they could be indicative of a clean layer; however, the opposite is true. The low returns are triggered by attenua- 

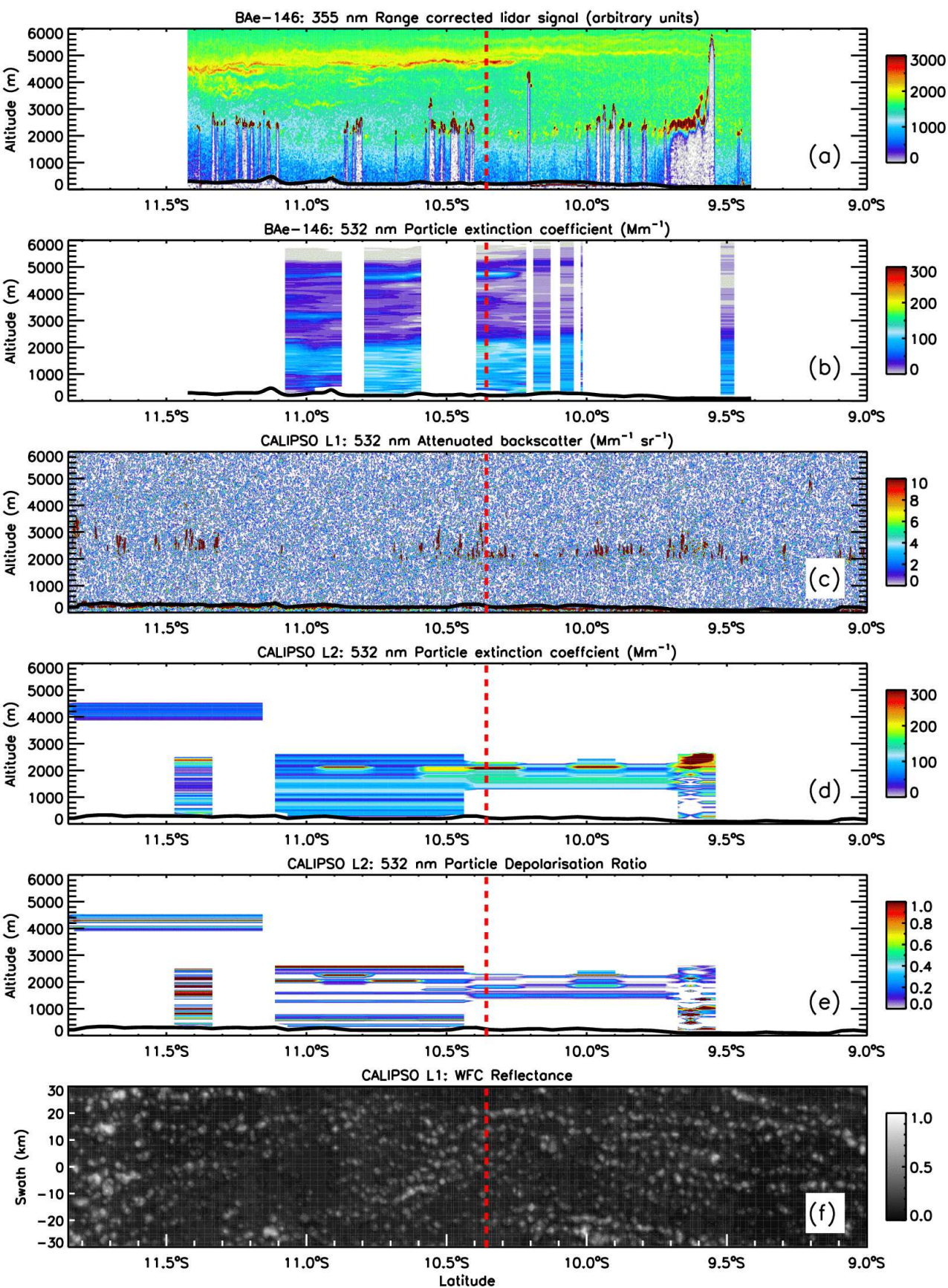

Figure 2. Latitude-height contour plots of quantities determined with the airborne and the spaceborne lidars: (a) Airborne lidar range corrected signal; (b) Airborne lidar extinction coefficient, converted to $532 \mathrm{~nm}$; (c) CALIPSO $532 \mathrm{~nm}$ attenuated backscatter (Level 1 data); (d) CALIPSO $532 \mathrm{~nm}$ extinction coefficient (Level 2 data); and (e) CALIPSO $532 \mathrm{~nm}$ particle depolarisation ratio (Level 2 data). Panel (f) displays the CALIPSO wide-field camera image in the $620-670 \mathrm{~nm}$ wavelength band (Level $1 \mathrm{data}, 1 \times 1 \mathrm{~km}$ native science data set). The dashed red vertical line indicates where the aircraft is flying closest to CALIPSO (coincidence).

tion through a moderately turbid layer, and are indicative of aerosol load. The information on the aerosol distribution can be better visualised in Fig. 2b, in terms of extinction coefficient, which can be interpreted in a more straightforward way. The aerosol signal shows an overall horizontal homo- geneity over the area under study, but a weak horizontal gradient can be observed for the elevated layer (thicker at the Southern end, and nearly indiscernible in the North).

It is interesting to compare this atmospheric structure to the CALIPSO returns, displayed in Fig. $2 \mathrm{c}$ in terms of the 
$532 \mathrm{~nm}$ attenuated backscatter (Level 1 data set). It is surprising to notice that none of the aerosol layers detected by airborne lidar are evident, and indeed only the cloud returns are apparent. This paper will show, however, that information about the atmospheric layers is not lost, but when it is displayed in this plot, the aerosol signal is hidden by the amplitude of shot noise.

Figure $2 \mathrm{~d}$ shows the result of the inversion into extinction coefficient, as computed with the CALIPSO algorithms (Level 2 data set, version 3.02). This product is designed to yield aerosol properties only, after the removal of cloud signals from the lidar returns. The following observations are made:

- An elevated layer at 4000-4500 m is observed at the Southern end. However, this layer is not detected at the other latitudes where the aircraft has observed it.

- Boundary layer aerosols are detected, but with some gaps that are not observed in the airborne data set. The gaps can be found in Fig. $2 \mathrm{~d}$ from 11.35 to $11.1^{\circ} \mathrm{S}$ (whole column); from 10.45 to $9.7^{\circ} \mathrm{S}$ (surface to $\sim$ $1300 \mathrm{~m}$ ); and from 9.55 to $9.4^{\circ} \mathrm{S}$ (whole column). They represent $\sim 30 \%$ of the boundary layer during the underflight.

- Large horizontal variations of the extinction coefficient are observed, mainly at the top of the boundary layer, which seem in contradiction with the general horizontal homogeneity over the region, seen in the airborne data.

The first two points can be understood in relation with CALIOP team presentations (Vaughan et al., 2009) and a comment in Pappalardo et al. (2010), where it is stated that not all structures in the CALIPSO Level 1 attenuated backscatter profiles get a representation in terms of Level 2 products, since the identification of features depends on their optical and geometrical properties, as well as the SNR. The SNR could be, for instance, reduced by cirrus above the aerosol layer (Kim et al., 2008); the CALIPSO data set was verified, however, and cirrus is not seen at the latitudes of the underflight with the research aircraft. A thin high cirrus (not shown here) is observed instead at the Southern latitudes, where the elevated layer is actually found in the Level 2 data as well. The gap between 10.45 and $9.7^{\circ} \mathrm{S}$ (below $\sim 1300 \mathrm{~m}$ ) can be better examined in connection with the findings of Vaughan et al. (2010): the CALIPSO version 3 layer detection scheme adds an aerosol base extender algorithm. If the base of an aerosol layer is within $2500 \mathrm{~m}$ of the surface, it is automatically extended down to the surface, unless the $532 \mathrm{~nm}$ integrated attenuated backscatter for the "gap" region is negative. For this profile, however, the Level 1 attenuated backscatter averaged over $80 \mathrm{~km}$ is positive and hence the layer base should have been extended down.

Note that the aerosol layers in the CALIPSO Level 2 data set generally show good quality indices for this scene. For all aerosol layers shown here, the extinction quality control flag is zero, meaning that the retrieval was unconstrained and did not require the iterative adaptation of the lidar ratio, and the extinction uncertainty is less than $0.5 \mathrm{~km}^{-1}$. Moreover, the cloud-aerosol discrimination (CAD) scores, Fig. 3a, suggest that there is little doubt about the layer classification as aerosol. The closer to -100 the CAD score, the higher the confidence that the observed layers should be treated as aerosols. All CAD scores for this scene fall below -93 , except for the layer displayed in orange colour for which $\mathrm{CAD}=-74$.

Examining only the CAD scores and the feature type given in the AVD flag (Fig. 3b) it could be concluded that cloud contamination of the profiles is negligible. However, this absence of clouds in the AVD feature type at $5 \mathrm{~km}$ resolution is misleading. Indeed, low-level clouds were detected by the airborne lidar (Fig. 2a) and are also evident in the Level 1 data set (Fig. 2c). The clouds were also detected by the CALIOP layer detection algorithm, and reported in the VFM, as seen in Fig. 3c, which is a high-resolution (singleshot) version of the AVD product. Moreover, when looking at the CALIPSO wide-field camera (WFC) the underlying cloud field is evident (Fig. 2f). Also, if one examines the AVD product on horizontal averaging, Fig. 3d, the detection of subgrid features at the single-shot level suggests the presence of a highly variable cloud field; this is not independent information, and it must be taken into account together with the feature type. Clouds detected at single-shot resolution below $4 \mathrm{~km}$ are removed from the Level 2 product before the computation of aerosol signals (Vaughan et al., 2009). In Winker et al. (2009) it is specified that boundary-layer clouds and the region of the atmosphere beneath them are identified and removed at single-shot resolution, allowing the retrieval of aerosols when the gaps between clouds are smaller than the required averaging interval. However, in cases where the cloud detection routine fails to identify a cloud (or imperfectly attributes the cloud boundaries), these clouds will not be removed from the surrounding aerosols layer. In these cases, significant discrepancies can be expected: imperfections of the layer detection algorithms will, in general, affect all the subsequent steps of the processing chain.

Concerning the large variability of the extinction coefficient, mentioned above, some insight can be given by the aerosol subtype, displayed in Fig. 3e. Part of the observed layers are correctly attributed as smoke, but for some layers the CALIPSO retrieval scheme "thinks" that it is in the presence of polluted dust. For each aerosol subtype, a different lidar ratio is assigned, as displayed in Fig. 3f: $70 \pm 28 \mathrm{sr}$ for smoke and $55 \pm 22$ sr for polluted dust (Omar et al., 2009; Lopes et al., 2013). The actual lidar ratio used in the retrieval may in principle be different than the initial one, due to the iterative adaptation applied in HERA in order to prevent divergent solutions; however, for this scene such an adaptation has not been applied. It is rather evident, by comparison with Fig. 2d, that the classification of what is a homogeneous 

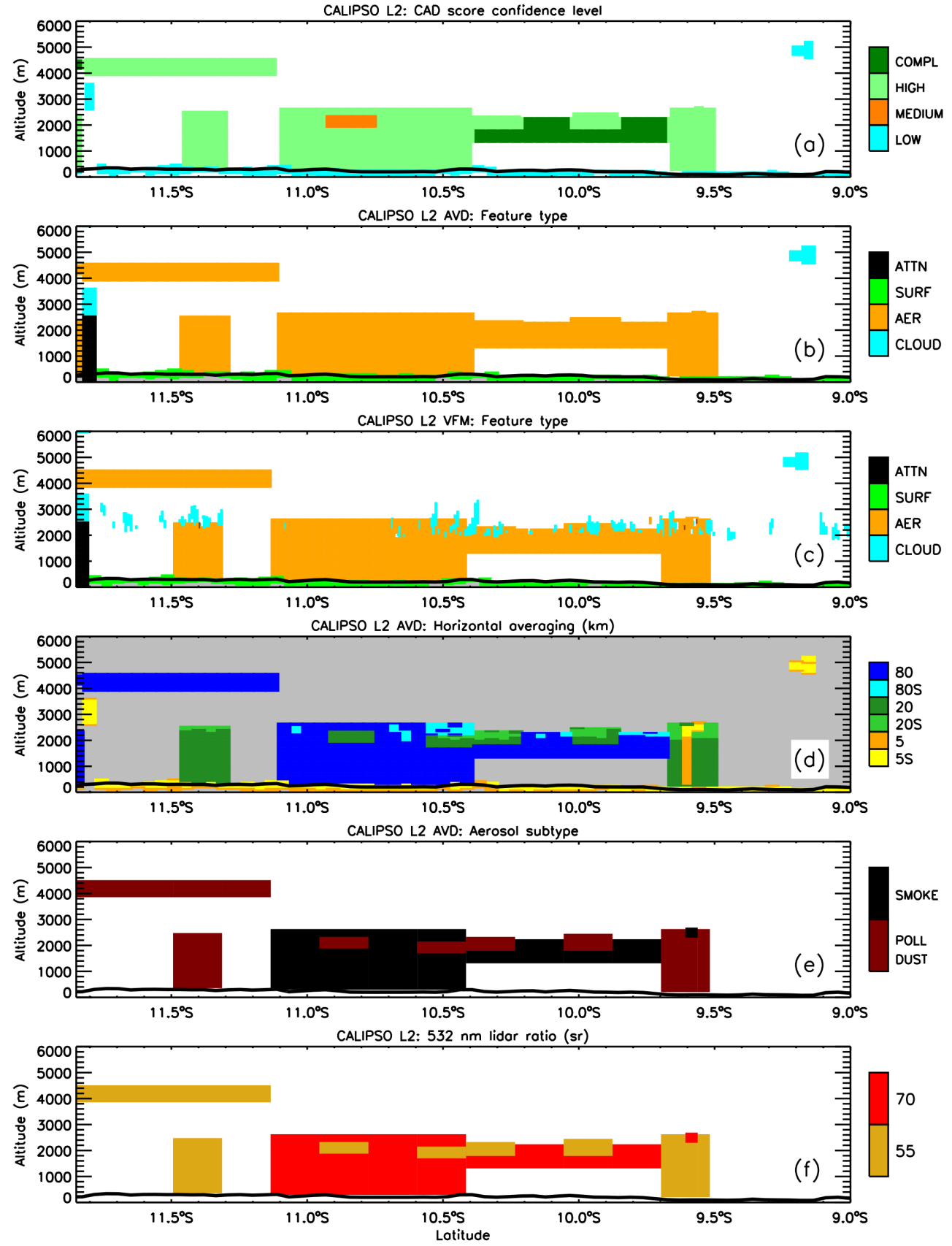

Figure 3. Latitude-height contour plots of some additional quantities determined from the CALIPSO Level 2 data set: (a) CAD score confidence level; (b) Feature type, as provided in the AVD flags; (c) Feature type, as provided in the VFM flags; (d) Horizontal averaging in km, as used for retrievals; (e) Aerosol subtype classification; and (f) Lidar ratio assigned for retrievals. An "S" in the horizontal averaging indicates that subgrid features have been detected at single-shot resolution. CAD score confidence levels are as follows: low, CAD > -20 ; medium, $-79 \leq \mathrm{CAD} \leq-20$; high, $-99 \leq \mathrm{CAD} \leq-80$; complete, $\mathrm{CAD}=-100$.

smoke layer into different aerosol subtypes is co-located with the large inhomogeneity in the retrieved extinction coefficients. The smoke plume is classified partly as smoke and partly as polluted dust, and when each layer is solved independently this unexpected result is found.
According to Omar et al. (2009, Fig. 2) the polluted dust type can only occur if the aerosol displays a depolarisation signal. An approximate particle depolarisation quantity is used, derived from the Level 1 volume depolarisation, and this approximation could lead to overestimation of the actual particle depolarisation and to corresponding clas- 
sification uncertainties. Recent validation results using airborne High Spectral Resolution Lidar (HSRL) co-located measurements show that CALIPSO's dust layers correspond to a classification of either dust or dust mixtures by the HSRL, and that the polluted dust type is overused due to an attenuation-related depolarisation bias (Burton et al., 2013). In the present study, depolarisation returns from the FAAM lidar show that aerosols observed in the Amazon basin during SAMBBA are non-depolarising; these observations seem confirmed in the CALIPSO Level 1 depolarisation product, although SNR is poor (not shown here).

Examining the Level 2 particle depolarisation product, presented in Fig. 2e, and which is considered more accurate than the approximation used in the aerosol subtyping algorithm, we find high depolarisation values. Even recomputing depolarisation according to Tesche et al. (2013) does not substantially alter the picture, and therefore particle depolarisation is, in this case, not thought to be dominated by the software bug highlighted in that paper. A large aerosol depolarisation signal is mainly found in the altitude range dominated by the broken low-level clouds, suggesting that the incorrect removal of the cloud signal has left some depolarisation signal in the aerosol product, causing its misclassification as polluted dust. In other words, the aerosol subtyping algorithm is affected by the previous steps in the CALIPSO data processing chain and these errors are a case of "garbage in, garbage out" (Omar et al., 2009; Liu et al., 2009). Moreover, this is a daytime observation and shot noise is certainly a major source of uncertainty.

In Fig. 4a all the extinction coefficient profiles are shown for the scene under study, as derived from the CALIPSO Level 2 profile product. This information is equivalent to Fig. 2d, and shows the very large variation in the retrieved profiles discussed above. The mean profile, resulting from spatially averaging the profiles, is shown in black; note that the profiles in this figure all have different horizontal extent, and hence a different weight in the averaging (they are weighed by horizontal extent). The mean profile is also shown in thick green in Fig. 4b, and is compared to the extinction profile derived from the mean aircraft lidar range corrected signal (indicated in red). The aircraft extinction coefficient shown in Figs. $2 b$ and $4 b$ was determined using the Marenco (2013) method, and has been multiplied by a colour ratio of 0.57 to convert it from 355 to $532 \mathrm{~nm}$. This conversion factor was determined from the Porto Velho AERONET site $\left(8^{\circ} 50^{\prime} \mathrm{S}, 63^{\circ} 56^{\prime} \mathrm{W}\right.$, located at $\sim 200 \mathrm{~km}$ from the aircraft measurements), where AOD at 18:00 UTC, interpolated for the 355 and $532 \mathrm{~nm}$ wavelengths yields 0.55 and 0.31 , respectively. The uncertainty range in Fig. $4 \mathrm{~b}$ indicates the effect on the retrieval of an assumed $\pm 50 \%$ error in the far end reference. This error accounts for considering a constant scattering ratio at the reference value, which is true only for a "well-mixed" layer. Its value has not been quantified and can be different than the assumed of $\pm 50 \%$. As this uncertainty is large near the surface, a verification has been performed
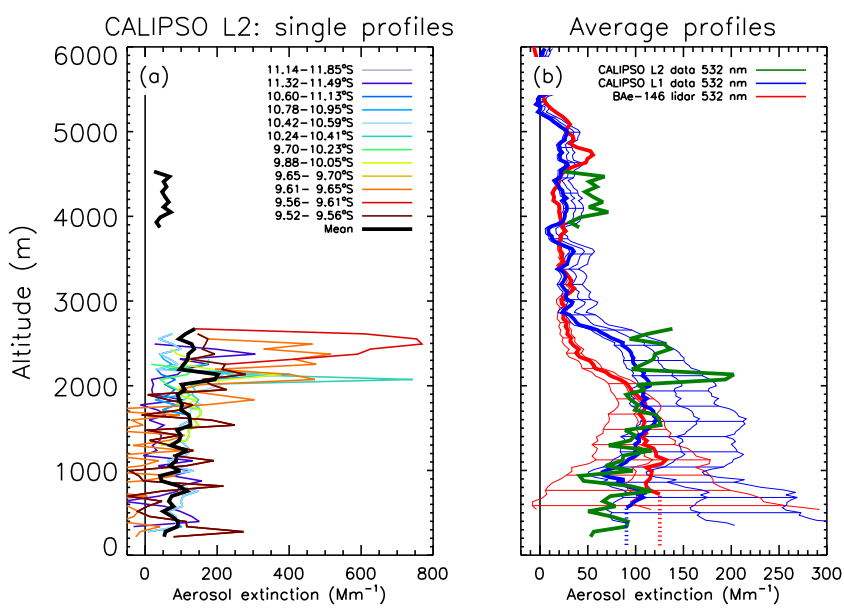

Figure 4. Profiles of aerosol extinction coefficient derived by lidar: (a) Individual vertical profiles given in the CALIPSO Level 2 data set. Thick black line: average profile for the latitude interval sampled by the aircraft; (b) Green line: average extinction profile from the CALIPSO Level 2 data, for the latitude interval sampled by the aircraft; blue lines: profiles derived from the CALIPSO Level 1 data set; red lines: profiles derived from the aircraft data set and converted to $532 \mathrm{~nm}$. The range of values indicated for the red and blue lines indicates the uncertainty due to the far end reference used for signal inversion, and the thick lines indicate the profiles constrained with AERONET. Note: for the purpose of constraining to AERONET, the lidar profile is prolonged with the dotted line (constant extinction) below the reference height.

using AERONET as a constraint; the red thick line indicates the lidar profile that matches the AERONET AOD (with no change of the lidar ratio). Note that the constrained retrieval is compatible with the unconstrained one; constraining to AERONET is however not a requirement of the method, but it helps reduce the uncertainty. In the boundary layer, the mean of the CALIPSO Level 2 profiles is generally in agreement with the aerosol extinction coefficient derived with the aircraft lidar after wavelength conversion.

An additional approach to the CALIPSO extinction retrieval was attempted, starting directly from the Level 1 data set shown in Fig. 2c. The first step involved cloud screening: all profiles presenting at least a point within the $1500-8000 \mathrm{~m}$ altitude range, that has an attenuated backscatter larger than $60 \mathrm{Mm}^{-1}$ in both the $532 \mathrm{~nm}$ and the $1064 \mathrm{~nm}$ channels, has been entirely removed before further processing. Note that while this simple thresholding scheme is demonstrably effective for this specific data segment, its general use in more complex scenes is not advocated. The remaining profiles (524 out of 671 , i.e. $80 \%$ ) have been averaged together to determine a mean attenuated backscatter for the scene, and this profile has been smoothed with a six-point running average (resulting vertical resolution: $180 \mathrm{~m}$ ). The signal has then been inverted into the aerosol extinction coefficient using the Marenco (2013) method, where the far-field boundary con- 
dition has been computed by assuming a constant scattering ratio over the 500-1200 $\mathrm{m}$ height interval, and the lidar ratio has been assumed to be $70 \mathrm{sr}$. The result of this procedure is shown in blue, and it is recognised that it offers a reasonable agreement with the latitudinally averaged Level 2 data, when uncertainties are accounted for.

Note that, for both the airborne and the spaceborne lidar, the retrieval constrained with AERONET falls well within the stated uncertainty lines obtained without a constraint. As expected with this method when unconstrained, uncertainty is large near the ground but it decreases when moving upwards.

Note also that between 2000 and $2800 \mathrm{~m}$ the extinction obtained for CALIPSO is larger than that obtained for the airborne lidar. A hypothesis is that it could be ascribed to the "twilight zone" consisting of hydrated aerosols in between the boundary-layer clouds (Koren et al., 2007); these hydrated aerosols could have different optical properties (lidar ratio and colour ratio) so as to introduce this discrepancy.

\section{Conclusions}

We believe that the data set presented here is a useful comparison and that it may help identify some critical points and develop further verification experiments. We have highlighted a particular type of scene, which yields retrieval problems in CALIPSO: the case of broken clouds embedded in a regional haze field, observed in daytime. Problems arise possibly due to the large amount of ambient daylight, limiting CALIOP's SNR. Reflection of light by the clouds amplifies the upwelling radiation and thus increases this effect; CALIOP's detection sensitivity may have been reduced below specifications for this reason, and this could explain why portions of aerosol layers visible in the aircraft data were not detected. Problems arise as well, because of uncertainties in the cloud-aerosol discrimination and aerosol subtype and lidar ratio selection algorithms: in this case, depolarisation by undetected boundary layer clouds may have mislead the algorithms into believing that dust is present over the Amazon, whereas the region was dominated by smoke.

Moreover, the retrieved aerosol extinction showed an excessive spatial variability. As determined with the aircraft instrument, however, the observed aerosols did not show a large horizontal inhomogeneity. A thin elevated aerosol layer (600 m deep, full width at half maximum) was observed at an altitude of $\sim 5 \mathrm{~km}$, with an AOD of 0.03 ; a $2.2 \mathrm{~km}$ deep boundary layer was also observed, featuring an aerosol extinction coefficient of $\sim 110 \mathrm{Mm}^{-1}$ and an AOD of $\sim 0.2$; the boundary layer is also topped with broken clouds (stratocumulus). The air layer between the boundary layer top and the elevated layer also showed aerosol content. From the observations gathered during SAMBBA, evidence exists that the aerosol layers are smoke from biomass burning, and that they do not depolarise backscatter lidar returns.
In this scene, the first remark is that CALIPSO does not detect the thin elevated layer. According to the aircraft data set, this layer has a peak backscatter coefficient of $0.8 \mathrm{Mm}^{-1} \mathrm{sr}^{-1}$ at $532 \mathrm{~nm}$ (horizontally averaged profile). This has to be compared to Winker et al. (2009, Fig. 4) and Vaughan et al. (2005, Fig. 2.4), where the CALIPSO detection sensitivity for the $532 \mathrm{~nm}$ backscatter coefficient at $5 \mathrm{~km}$ altitude in daytime is estimated at $1.5,0.8$, and $0.35 \mathrm{Mm}^{-1} \mathrm{sr}^{-1}$ for horizontal resolutions of 5,20 , and $80 \mathrm{~km}$, respectively: according to these specifications, the layer should have been detected at the coarser resolutions. Note that the daytime sensitivity thresholds for feature detection are larger than the night-time ones; this is an effect of the background radiation due to daylight, which acts as a disturbance to the lidar measurements. The clouds underneath may have played a role in this failure to detect, as they increase the diffuse daylight background, reducing CALIOP's SNR and hence detection sensitivity. Vaughan et al. (2005) specify that the above specifications on detection sensitivity apply for a $5 \%$ columnar albedo; in the present scene, dominated by low-level clouds, the average albedo is most probably larger.

The second remark is that the CALIPSO data set displays a variable aerosol subtype in what appears to be a homogeneous scene. We believe that the presence of broken clouds at the top of the boundary layer misleads the CALIPSO automated processing scheme: if the clouds are incorrectly removed, an apparent aerosol depolarisation is detected and the aerosol layer receives a classification as polluted dust, and thus a reduced lidar ratio and a lower extinction. Cases of aerosols being misclassified as dust or polluted dust have also been reported in the literature, but in those studies classification errors have a different explanation than in the present case. Kacenelenbogen et al. (2011) have identified an underestimate of the lidar ratio assigned for retrievals in HERA, due to a misclassification of fine absorbing aerosols as dust or polluted dust, when compared to HSRL; as however no coincidence with clouds is reported, we believe that the causes of misclassification in that article should be different than those reported here. In Tesche et al. (2013) a similar misclassification of marine aerosols was observed in the presence of clouds, but the reason for this was identified to be a software bug, and hence was not ascribed to an incorrect removal of the cloud field. The case illustrated here suggests the incorporation of WFC radiances in the cloud detection scheme could lead to a potential improvement of the final product. Moreover, the range bins for which clouds have been detected and removed at single-shot resolution are identified in the AVD product (Fig. 3d): data users could conceivably apply this information to derive more rigorous quality assurance screening criteria.

The third remark is that the boundary layer extinction coefficient determined in the CALIPSO data set yields a consistent average field when compared to the aircraft lidar and accounting for the longer wavelength. However, taking into account that the boundary layer aerosol detection misses its 
extent by $\sim 30 \%$, it must be concluded that the along-track aerosol optical depth estimate from the Level 2 data for this particular scene is about two thirds of what is expected. The CALIPSO extinction data set also shows a large spatial variability in both the horizontal and vertical directions, which is not reflected in the aircraft data set. We believe that this is due to the large shot noise for these daytime measurements and to the variable aerosol subtype, and subsequently to the different lidar ratios used.

Finally, we note that CALIPSO observations can be reprocessed from the Level 1 data (attenuated backscatter data), using published methods for backscatter lidar; this was also performed by Kacenelenbogen et al. (2011), although in that article an outward integration scheme is used. A reprocessing of this kind cannot be easily automated and requires interaction by an expert for tasks such as integration, cloud filtering, selection of a reference layer and a lidar ratio, etc.; but in specific scenarios it can help gain insight into the aerosol vertical distribution, and it permits comparing results with an inward solution scheme, which represents a stable mathematical solution.

Spaceborne lidar is a great advance for science, and in the last seven years CALIPSO has given researchers a very useful data set, mapping global aerosols in 3-D at high resolution. It is therefore important to identify critical issues, so as to enable improvement of the data products. Scenes, such as that noted here, are not infrequent, and misrepresentations such as the one highlighted will yield an incorrect evaluation of the regional radiative forcing and of the aerosol indirect effect. Ideas for improving the exploitation of the CALIPSO data set have also been presented.

Acknowledgements. We thank the ICARE Data and Services Center and the NASA/LaRC Science Data Center for providing access to the CALIPSO data used in this study. AERONET data at Porto Velho are a courtesy of NASA and Paulo Artaxo. Airborne data were obtained using the BAe-146-301 Atmospheric Research Aircraft (ARA) flown by Directflight Ltd and managed by the Facility for Airborne Atmospheric Measurements (FAAM), which is a joint entity of the Natural Environment Research Council (NERC) and the Met Office. SAMBBA was funded by the Met Office and NERC (grant NE/J009822/1)

Edited by: H. Coe

\section{References}

Allen, G., Illingworth, S. M., O'Shea, S. J., Newman, S., Vance, A., Bauguitte, S. J.-B., Marenco, F., Kent, J., Bower, K., Gallagher, M. W., Muller, J., Percival, C. J., Harlow, C., Lee, J., and Taylor, J. P.: Atmospheric composition and thermodynamic retrievals from the ARIES airborne TIR-FTS system - Part 2: Validation and results from aircraft campaigns, Atmos. Meas. Tech. Discuss., 7, 3397-3441, doi:10.5194/amtd-7-3397-2014, 2014.
Amiridis, V., Tsekeri, A., Marenco, F., Marinou, E., Giannakaki, E., Balis, D., Nenes, A., Allan, J., Bacak, A., and Coe, H.: Validation of CALIPSO nighttime aerosol products using airborne lidar and in-situ observations, in: Proceedings, International Laser Radar Conference 2012, National Technical University of Athens, Athens, Greece, 2012.

Amiridis, V., Wandinger, U., Marinou, E., Giannakaki, E., Tsekeri, A., Basart, S., Kazadzis, S., Gkikas, A., Taylor, M., Baldasano, J., and Ansmann, A.: Optimizing CALIPSO Saharan dust retrievals, Atmos. Chem. Phys., 13, 12089-12106, doi:10.5194/acp-1312089-2013, 2013.

Anderson, T. L., Charlson, R. J., Winker, D. M., Ogren, J. A., and Holmén, K.: Mesoscale Variations of Tropospheric Aerosols, J. Atmos. Sci., 60, 119-136, 2003.

Andreae, M. O., Rosenfeld, D., Artaxo, P., Costa, A. A., Frank, G. P., Longo, K. M., and Silva-Dias, M. A. F.: Smoking Rain Clouds over the Amazon, Science, 303, 1337-1342, 2004.

Angelo, C.: Amazon fire analysis hits new heights, Nature News, doi:10.1038/nature.2012.11467, 2012.

Baars, H., Ansmann, A., Althausen, D., Engelmann, R., Heese, B., Müller, D., Artaxo, P., Paixao, M., Pauliquevis, T., and Souza, R.: Aerosol profiling with lidar in the Amazon Basin during the wet and dry season, J. Geophys. Res., 117, D21201, doi:10.1029/2012JD018338, 2012.

Burton, S. P., Ferrare, R. A., Vaughan, M. A., Omar, A. H., Rogers, R. R., Hostetler, C. A., and Hair, J. W.: Aerosol classification from airborne HSRL and comparisons with the CALIPSO vertical feature mask, Atmos. Meas. Tech., 6, 1397-1412, doi:10.5194/amt-6-1397-2013, 2013

Chand, D., Anderson, T. L., Wood, R., Charlson, R. J., Hu, Y., Liu, Z., and Vaughan, M.: Quantifying above-cloud aerosol using spaceborne lidar for improved understanding of cloudysky direct climate forcing, J. Geophys. Res., 113, D13206, doi:10.1029/2007JD009433, 2008.

Chazette, P., Dabas, A., Sanak, J., Lardier, M., and Royer, P.: French airborne lidar measurements for Eyjafjallajökull ash plume survey, Atmos. Chem. Phys., 12, 7059-7072, 2012, http://www.atmos-chem-phys.net/12/7059/2012/.

Fernald, F. G.: Analysis of atmospheric lidar observations: some comments, Appl. Opt., 23, 652-653, 1984.

Forster, P., Ramaswamy, V., Artaxo, P., Berntsen, T., Betts, R., Fahey, D., Haywood, J., Lean, J., Lowe, D., Myhre, G., Nganga, J., Prinn, R., Raga, G., Schulz, M., and Dorland, R. V.: Changes in Atmospheric Constituents and in Radiative Forcing, in: Climate Change 2007: The Physical Science Basis. Contribution of Working Group I to the Fourth Assessment Report of the Intergovernmental Panel on Climate Change, edited by: Solomon, S., Qin, D., Manning, M., Chen, Z., Marquis, M., Averyt, K. B., Tignor, M., and Miller, H. L., Cambridge University Press, Cambridge, 2007.

Freitas, S. R., Longo, K. M., Chatfield, R., Latham, D., Silva Dias, M. A. F., Andreae, M. O., Prins, E., Santos, J. C., Gielow, R., and Carvalho Jr., J. A.: Including the sub-grid scale plume rise of vegetation fires in low resolution atmospheric transport models, Atmos. Chem. Phys., 7, 3385-3398, doi:10.5194/acp-7-3385-2007, 2007.

Gerbig, C., Kley, D., VolzThomas, A., Kent, J., Dewey, K., and McKenna, D. S.: Fast response resonance fluorescence CO measurements aboard the C-130: Instrument characterization and 
measurements made during North Atlantic Regional Experiment 1993, J. Geophys. Res., 101, 29229-29238, 1996.

Gerbig, C., Schmitgen, S., Kley, D., Volz-Thomas, A., Dewey, K., and Haaks, D.: An improved fast-response vacuum-UV resonance fluorescence CO instrument, J. Geophys. Res., 104, 1699-1704, 1999.

Groß, S., Freudenthaler, V., Wiegner, M., Gasteiger, J., Geiß, A., and Schnell, F.: Dual-wavelength linear depolarization ratio of volcanic aerosols: Lidar measurements of the Eyjafjallajökull plume over Maisach, Germany, Atmos. Environ., 48, 85-96, 2012.

Houghton, J. T., Ding, Y., Griggs, D. J., Noguer, M., van der Linden, P. J., Dai, X., Maskell, K., and Johnson, C. A. (Eds.): Climate Change 2001: The scientific basis, Cambridge University Press, Cambridge, 2001.

Hunt, W. H., Winker, D. M., Vaughan, M. A., Powell, K. A., Luckeri, P. L., and Weimer, C.: CALIPSO Lidar Description and Performance Assessment, J. Atmos. Ocean. Tech., 26, 1214-1228, 2009.

Jethva, H., Torres, O., Waquet, F., Chnd, D., and Hu, Y.: How do Atrain sensors intercompare in the retrieval of above-cloud aerosol optical depth? A case study-based assessment, Geophys. Res. Lett., 41, 186-192, 2014.

Johnson, B., Haywood, J., Longo, K., Coe, H., Artaxo, P., Morgan, W., and Freitas, S.: Overview of the South American Biomass Burning Analysis (SAMBBA) field experiment in Brazil during Sept-Oct 2012, Geophys. Res. Abs., 15, EGU2013-7087-1, 2013.

Kacenelenbogen, M., Vaughan, M. A., Redemann, J., Hoff, R. M., Rogers, R. R., Ferrare, R. A., Russell, P. B., Hostetler, C. A., Hair, J. W., and Holben, B. N.: An accuracy assessment of the CALIOP/CALIPSO version 2/version 3 daytime aerosol extinction product based on a detailed multi-sensor, multi-platform case study, Atmos. Chem. Phys., 11, 3981-4000, doi:10.5194/acp-11-3981-2011, 2011.

Kim, M.-H., Kim, S.-W., Yoon, S.-C., and Omar, A. H.: Comparison of aerosol optical depth between CALIOP and MODIS-Aqua for CALIOP aerosol subtypes over the ocean, J. Geophys. Res.Atmos., 118, 13241-13252, 2013.

Kim, S.-W., Berthier, S., Raut, J.-C., Chazette, P., Dulac, F., and Yoon, S.-C.: Validation of aerosol and cloud layer structures from the space-borne lidar CALIOP using a ground-based lidar in Seoul, Korea, Atmos. Chem. Phys., 8, 3705-3720, doi:10.5194/acp-8-3705-2008, 2008.

Kittaka, C., Winker, D. M., Vaughan, M. A., Omar, A., and Remer, L. A.: Intercomparison of column aerosol optical depths from CALIPSO and MODIS-Aqua, Atmos. Meas. Tech., 4, 131-141, doi:10.5194/amt-4-131-2011, 2011.

Koren, I., Remer, L. A., Kaufman, Y. J., Rudich, Y., and Martins, J. V.: On the twilight zone between clouds and aerosols, Geophys. Res. Lett., 34, L08805, doi:10.1029/2007GL029253, 2007.

Koren, I., Martins, J. V., Remer, L. A., and Afargan, H.: Smoke Invigoration Versus Inhibition of Clouds over the Amazon, Science, 321, 946-949, 2008.

Labonne, M., Breon, F.-M., and Chevallier, F.: Injection height of biomass burning aerosols as seen from a spaceborne lidar, Geophys. Res. Lett., 34, L11806, doi:10.1029/2007GL029311, 2007.

Lance, S., Brock, C. A., Rogers, D., and Gordon, J. A.: Water droplet calibration of the Cloud Droplet Probe (CDP) and in- flight performance in liquid, ice and mixed-phase clouds during ARCPAC, Atmos. Meas. Tech., 3, 1683-1706, doi:10.5194/amt3-1683-2010, 2010.

Liu, P. S. K., Leaitch, W. R., Strapp, J. W., and Wasey, M. A.: Response of particle measuring systems airborne ASASP and PCASP to $\mathrm{NaCl}$ and latex particles, Aerosol Sci. Tech., 16, 83-95, 1992.

Liu, Z., Vaughan, M., Winker, D., Kittaka, C., Getzewich, B., Kuehn, R., Omar, A., Powell, K., Trepte, C., and Hostetler, C.: The CALIPSO lidar cloud and aerosol discrimination: Version 2 algorithm and initial assessment of performance, J. Atmos. Ocean. Tech., 26, 1198-1213, 2009.

Lopes, F. J. S., Landulfo, E., and Vaughan, M. A.: Evaluating CALIPSO's $532 \mathrm{~nm}$ lidar ratio selection algorithm using AERONET sun photometers in Brazil, Atmos. Meas. Tech., 6, 3281-3299, doi:10.5194/amt-6-3281-2013, 2013.

Marenco, F.: Nadir airborne lidar observations of deep aerosol layers, Atmos. Meas. Tech., 6, 2055-2064, doi:10.5194/amt-62055-2013, 2013.

Marenco, F., Johnson, B., Turnbull, K., Newman, S., Haywood, J., Webster, H., and Ricketts, H.: Airborne Lidar Observations of the 2010 Eyjafjallajökull Volcanic Ash Plume, J. Geophys. Res., 116, D00U05, doi:10.1029/2011JD016396, 2011.

Mattis, I., Ansmann, A., Wandinger, U., and Müller, D.: Unexpectedly high aerosol load in the free troposphere over central Europe in spring/summer 2003, Geophys. Res. Lett., 30, 2178, doi:10.1029/2003GL018442, 2003.

Mielonen, T., Arola, A., Komppula, M., Kukkonen, J., Koskinen, J., de Leeuw, G., and Lehtinen, K. E.: Comparison of CALIOP level 2 aerosol subtypes to aerosol types derived from AERONET inversion data, Geophys. Res. Lett., 36, L18804, doi:10.1029/2009GL039609, 2009.

Müller, D., Mattis, I., Wandinger, U., Ansmann, A., Althausen, D., and Stohl, A.: Raman lidar observations of aged Siberian and Canadian forest fire smoke in the free troposphere over Germany in 2003: Microphysical particle characterization, J. Geophys. Res., 110, D17201, doi:10.1029/2004JD005756, 2005.

Omar, A. H., Winker, D. M., Kittaka, C., Vaughan, M. A., Liu, Z., Hu, Y., Trepte, C. R., Rogers, R. R., Ferrare, R. A., Lee, K.-P., Kuehn, R. E., and Hostetler, C. A.: The CALIPSO Automated Aerosol Classification and Lidar Ratio Selection Algorithm, J. Atmos. Ocean. Tech., 26, 1994-2014, 2009.

Omar, A. H., Winker, D. M., Tackett, J. L., Giles, D. M., Kar, J., Liu, Z., Vaughan, M. A., Powell, K. A., and Trepte, C. R.: CALIOP and AERONET aerosol optical depth comparisons: one size fits none, J. Geophys. Res.-Atmos., 118, 4748-4766, 2013.

Osborne, S. R., Abel, S. J., Boutle, I. A., and Marenco, F.: Evolution of Stratocumulus Over Land: Comparison of Ground and Aircraft Observations with Numerical Weather Prediction Simulations, Bound.-Lay. Meteor., doi:10.1007/s10546-014-9944-0, 2014.

Palmer, P. I., Parrington, M., Lee, J. D., Lewis, A. C., Rickard, A. R., Bernath, P. F., Duck, T. J., Waugh, D. L., Tarasick, D. W., Andrews, S., Aruffo, E., Bailey, L. J., Barrett, E., Bauguitte, S. J.-B., Curry, K. R., Di Carlo, P., Chisholm, L., Dan, L., Forster, G., Franklin, J. E., Gibson, M. D., Griffin, D., Helmig, D., Hopkins, J. R., Hopper, J. T., Jenkin, M. E., Kindred, D., Kliever, J., Le Breton, M., Matthiesen, S., Maurice, M., Moller, S., Moore, D. P., Oram, D. E., O’Shea, S. J., Owen, R. C., Pagniello, C. 
M. L. S., Pawson, S., Percival, C. J., Pierce, J. R., Punjabi, S., Purvis, R. M., Remedios, J. J., Rotermund, K. M., Sakamoto, K. M., da Silva, A. M., Strawbridge, K. B., Strong, K., Taylor, J., Trigwell, R., Tereszchuk, K. A., Walker, K. A., Weaver, D., Whaley, C., and Young, J. C.: Quantifying the impact of BOReal forest fires on Tropospheric oxidants over the Atlantic using Aircraft and Satellites (BORTAS) experiment: design, execution and science overview, Atmos. Chem. Phys., 13, 6239-6261, doi:10.5194/acp-13-6239-2013, 2013.

Pappalardo, G., Wandinger, U., Mona, L., Hiebsch, A., Mattis, I., Amodeo, A., Ansmann, A., Seifert, P., Linné, H., Apituley, A., Arboledas, L. A., Balis, D., Chaikovsky, A., D’Amico, G., Tomasi, F. D., Freudenthaler, V., Giannakaki, E., Giunta, A., Grigorov, I., Iarlori, M., Madonna, F., Mamouri, R.-E., Nasti, L., Papayannis, A., Pietruczuk, A., Pujadas, M., Rizi, V., Rocadenbosch, F., Russo, F., Schnell, F., Spinelli, N., Wang, X., and Wiegner, M.: EARLINET correlative measurements for CALIPSO: First intercomparison results, J. Geophys. Res., 115, D00H19, doi:10.1029/2009JD012147, 2010.

Powell, K. A., Hostetler, C. A., Liu, Z., Vaughan, M. A., Kuehn, R. E., Hunt, W. H., Lee, K.-P., Trepte, C. R., Rogers, R. R., Young, S. A., and Winker, D. M.: CALIPSO lidar calibration algorithms. Part I: Nighttime 532-nm parallel channel and 532-nm perpendicular channel, J. Atmos. Ocean. Tech., 26, 2015-2033, 2009.

Redemann, J., Vaughan, M. A., Zhang, Q., Shinozuka, Y., Russell, P. B., Livingston, J. M., Kacenelenbogen, M., and Remer, L. A.: The comparison of MODIS-Aqua (C5) and CALIOP (V2 \& V3) aerosol optical depth, Atmos. Chem. Phys., 12, 3025-3043, doi:10.5194/acp-12-3025-2012, 2012.

Schuster, G. L., Vaughan, M., MacDonnell, D., Su, W., Winker, D., Dubovik, O., Lapyonok, T., and Trepte, C.: Comparison of CALIPSO aerosol optical depth retrievals to AERONET measurements, and a climatology for the lidar ratio of dust, Atmos. Chem. Phys., 12, 7431-7452, doi:10.5194/acp-12-7431-2012, 2012.

Sofiev, M., Ermakova, T., and Vankevich, R.: Evaluation of the smoke-injection height from wild-land fires using remote-sensing data, Atmos. Chem. Phys., 12, 1995-2006, doi:10.5194/acp-12-1995-2012, 2012.

Stocker, T. F., Qin, D., Plattner, G.-K., Tignor, M. M., Allen, S. K., Boschung, J., Nauels, A., Xia, Y., Bex, V., and Midgley, P. M.: Climate change 2013: The physical science basis, Unedited online version (www.ipcc.ch/report/ar5/wg1/), 2013.

Tesche, M., Wandinger, U., Ansmann, A., Althausen, D., Müller, D., and Omar, A. H.: Ground-based validation of CALIPSO observations of dust and smoke in the Cape Verde region, J. Geophys. Res.-Atmos., 118, 2889-2902, 2013.
Textor, C., Schulz, M., Guibert, S., Kinne, S., Balkanski, Y., Bauer, S., Berntsen, T., Berglen, T., Boucher, O., Chin, M., Dentener, F., Diehl, T., Easter, R., Feichter, H., Fillmore, D., Ghan, S., Ginoux, P., Gong, S., Grini, A., Hendricks, J., Horowitz, L., Huang, P., Isaksen, I., Iversen, I., Kloster, S., Koch, D., Kirkevåg, A., Kristjansson, J. E., Krol, M., Lauer, A., Lamarque, J. F., Liu, X., Montanaro, V., Myhre, G., Penner, J., Pitari, G., Reddy, S., Seland, Ø., Stier, P., Takemura, T., and Tie, X.: Analysis and quantification of the diversities of aerosol life cycles within AeroCom, Atmos. Chem. Phys., 6, 1777-1813, doi:10.5194/acp-6-1777-2006, 2006.

Vaughan, M., Kuehn, R., Tackett, J., Rogers, R., Liu, Z., Omar, A., Getzewich, B., Powell, K., Hu, Y., Young, S., Avery, M., Winker, D., and Trepte, C.: Strategies for improved CALIPSO aerosol optical depth estimates, in: Proceedings, International Laser Radar Conference 2010, Curran Associates, Red Hook, NY, 2010.

Vaughan, M. A., Winker, D. M., and Powell, K. A.: CALIOP Algorithm Theoretical Basis Document. Part 2: Feature Detection and Layer Properties Algorithms, NASA Langley Research Center (PC-SCI-202 Part 2, Release 1.01), Hampton, Virginia, 2005.

Vaughan, M. A., Powell, K. A., Kuehn, R. E., Young, S. A., Winker, D. M., Hostetler, C., Hunt, W. H., Liu, Z., McGill, M. J., and Getzewich, B. J.: Fully automated detection of cloud and aerosol layers in the CALIPSO lidar measurements, J. Atmos. Ocean. Tech., 26, 2034-2050, 2009.

Winker, D. M., Vaughan, M. A., Omar, A., Hu, Y., Powell, K. A., Liu, Z., Hunt, W. H., and Young, S. A.: Overview of the CALIPSO Mission and CALIOP Data Processing Algorithms, J. Atmos. Ocean. Tech., 26, 2310-2323, 2009.

Winker, D. M., Pelon, J., Coakley Jr., J. A., Ackerman, S. A., Charlson, R. J., Colargo, P. R., Flamant, P., Fu, Q., Hoff, R. M., Kittaka, C., Kubar, T. L., Le Treut, H., McCormick, M. P., Mégie, G., Poole, L., Powell, K., Trepte, C., Vaughan, M. A., and Wielicki, B. A.: The CALIPSO mission: A Global 3D View of Aerosols and Clouds, B. Am. Meteor. Soc., 91, 1211-1228, 2010.

Winker, D. M., Tackett, J. L., Getzewich, B. J., Liu, Z., Vaughan, M. A., and Rogers, R. R.: The global 3-D distribution of tropospheric aerosols as characterized by CALIOP, Atmos. Chem. Phys., 13, 3345-3361, doi:10.5194/acp-13-3345-2013, 2013.

Young, S. A. and Vaughan, M. A.: The retrieval of profiles of particulate extinction from Cloud-Aerosol Lidar Infrared Pathfinder Satellite Observations (CALIPSO) data: Algorithm description, J. Atmos. Ocean. Tech., 26, 1105-1119, 2009.

Young, S. A., Vaughan, M. A., Kuehn, R. E., and Winker, D. M.: The retrieval of profiles of particulate extinction from CloudAerosol Lidar and Infrared Pathfinder Observations (CALIPSO) data: Uncertainty and error sensitivity analyses, J. Atmos. Ocean. Tech., 30, 395-428, 2013. 